\title{
México y el Acuerdo de Asociación Transpacífico (TPP): oportunidades y retos
}

\section{Resumen}

En el ensayo se describen las principales características del Acuerdo de Asociación Transpacífico (TPP, por sus siglas en inglés), su origen, el alcance geográfico, poblacional y en términos de comercio global, así como algunas similitudes y diferencias con otros mecanismos regionales que involucran la Cuenca del Pacífico y el estado actual de estas negociaciones. Posteriormente se analizan dos temas cruciales para México: ¿cuál es la lógica geopolítica de la participación mexicana en el TPP? ¿Qué lugar ocupa el TPP en el proyecto de desarrollo y de política exterior de México? Consideraciones finales matizarán las perspectivas optimistas y pesimistas de la participación de México en este acuerdo transhemisférico.

Palabras clave: TPP, Cuenca del Pacífico, Acuerdo de Asociación Transpacífico.

\section{Abstract. México and the Trans-Pacific Partnership (TPP): Opportunities and Challenges}

This essay inquiries into the main features of the Trans-Pacific Partnership, its origin, its reach in terms of geography, potential population coverage and global trade, as well as the uniqueness and similarities with other regional integration mechanisms for the Pacific Rim. After reviewing the state of the recent negotiation process, the analysis focused on two crucial issues for Mexico, namely, what is the geopolitical logic of Mexico's participation in the

Artículo recibido el 05 de septiembre de 2013 y dictaminado el 15 de octubre de 2013.

1. Programa de Estudios Asia Pacífico, Departamento Académico de Estudios Internacionales, ITAM. 
TPP? Where the TPP stands within Mexico's current development project and foreign policy? A concluding section balances optimist and pessimist prospects for Mexico's participation in this trans-hemispheric future agreement.

Keywords: TPP, Pacific Rim, Trans-Pacific Partnership.

\section{Introducción}

En un mundo multipolar caracterizado desde hace ya más de dos décadas por la existencia de propuestas sólidas de integración económica regional, México se ha insertado desde 2012 en las negociaciones del Acuerdo de Asociación Transpacífico (TPР), un acuerdo en el que 12 naciones de la Cuenca del Pacífico intentan establecer una de las zonas de libre comercio más grandes del mundo. El TPP, un acuerdo internacional de próxima generación, tiene, sin embargo, objetivos más ambiciosos: redefinir las relaciones comerciales, económicas, políticas y jurídicas entre las naciones de esta gigantesca zona Asia Pacífico.

Ante la imposibilidad de las economías pertenecientes del Mecanismo de Cooperación Asia Pacífico (APEC, por sus siglas en inglés) de alcanzar las Metas Bogor para el año 2020 sobre liberalización del comercio regional y ante el evidente fracaso de la Ronda Doha de la Organización Mundial del Comercio (OMC), el TPP se perfila como uno de los instrumentos más tangibles para alcanzar objetivos de liberalización de flujos comerciales y de inversión en la región, garantizar certidumbre en las inversiones de empresas transnacionales, elevar los estándares laborales y medioambientales en países de la región, y garantizar los derechos de propiedad intelectual en una era tecnológica donde es necesario redefinir diversas actividades económicas.

Desafortunadamente el proceso de negociación, que parecía estar programado para alcanzar su culminación a finales de 2013, se caracteriza por su secretismo, falta de transparencia y por ser eminentemente antidemocrático (no cuenta con la participación real y constante de la población ante quienes sus gobiernos deben rendir cuentas). A pesar de los constantes comunicados sobre las rondas desde 2010, en realidad casi nada se sabe de las negociaciones y de las posturas detalladas de cada país. Bajo la premisa de que la confidencialidad es crucial para el éxito de la negociación, poco se sabe del contenido de las rondas de negociación y sólo se conocen dos capítulos por filtraciones de los borradores de "Propiedad intelectual e inversiones", los cuales, peor aún, revelan amenazas muy graves para los intereses nacionales 
y cuestionan la futura capacidad del Estado de legislar en el interés público y afectan la soberanía nacional.

Ante esta situación es importante indagar en las razones y la lógica de la inserción de México en este pacto transhemisférico, los objetivos que persigue el país en su participación, y sobre todo el lugar que ocupa el TPP en el proyecto de desarrollo y en la política exterior de la actual administración. La premisa guía de este estudio es que, por un lado, las verdaderas negociaciones confidenciales del TPP las encabeza Estados Unidos y, ahora que Japón ha entrado al proceso negociador, importantes obstáculos son cada vez más evidentes en el sector agrícola, entre otros. Por otro lado, la participación de México obedece a objetivos muy claros dentro del Plan Nacional de Desarrollo (PND), aunque no es claro todavía si el optimismo que hay en el dinamismo económico de la región Asia Pacífico será justificación suficiente para incorporar a toda costa al país en este acuerdo que involucra mucho más que libre comercio.

El ensayo está dividido en dos grandes apartados. En la primera parte se revisa el origen, evolución y lógica actual que justifica la aceptación de 12 economías de la región a un acuerdo de esta magnitud, comparando la particularidad y similitud del TPP con otras propuestas de integración regional Asia Pacífico (en particular ASEAN, EAS, Alianza del Pacífico y el RCEP), para posteriormente hacer una revisión general, contando con la poca información vertida fuera de las mesas de trabajo, del estado de las negociaciones hasta ahora.

En un segundo apartado, se analiza la lógica geopolítica de la inserción de México al TPP desde 2012 bajo la premisa básica de que el libre comercio es, per se, condición suficiente para justificar la búsqueda de este tipo de mecanismos de integración comercial regional, así como el lugar privilegiado que ya tiene el TPP en el discurso oficial y en el PND. De ahí que, se estudia el lugar que ocupa este futuro acuerdo internacional dentro del proyecto de desarrollo nacional y dentro de los objetivos de la política exterior mexicana. Se evaluarán los límites de la llamada inserción de México en los mercados de Asia Pacífico dentro del marco del TPP y los riesgos que podría correr no sólo la economía del país, sino el propio proyecto de desarrollo deseado en el PND. Entre las consideraciones finales está el escepticismo de que se alcance a firmar el acuerdo a finales de 2013, una revisión de los puntos más ríspidos en las negociaciones actuales entre las delegaciones, el futuro del TPP sin la presencia de China, la segunda economía del mundo, e importantes implicaciones para México en el futuro. 


\section{El TPP como propuesta transhemisférica}

El origen de este acuerdo regional data de 2002, cuando en Los Cabos (Baja California), Singapur, Nueva Zelanda y Chile acordaron iniciar negociaciones de asociación económica, el Pacific Three Closer Economic Partnership P3-CEP (Uscanga, 2011: 3). Este paso, formalizado en 2003 para encontrar formas de liberalizar el comercio en la región Asia Pacífico, contó con el interés inmediato de Brunei Darussalam. Posterior a su adhesión, se suscribió finalmente en 2005 el Acuerdo Estratégico Transpacífico de Asociación Económica (el entonces también llamado Pacific Four -P4), el cual entró en vigor un año después en 2006.

Sin embargo, el verdadero impulso del TPP ocurre cuando Washington expresa su interés por la zona de Asia Pacífico. En marzo de 2008 Estados Unidos se unió a estas negociaciones: el presidente George W. Bush informó al Congreso el 22 de septiembre de ese año la intención de su país de negociar el TPP, particularmente en el sector de inversión y servicios financieros (Fergusson, 2011:1 y 4). Esta decisión fue refrendada por el actual presidente Barack Obama dentro de la estrategia global de su país de redirigir ahora su atención a esa región del globo. Una vez que Estados Unidos expresó su interés por el TPP, similares decisiones han tomado otros países. Desde noviembre del mismo año, Australia, Perú y Vietnam participan en estas rondas. Dos años después, en octubre de 2010, Malasia se adhirió al proceso negociador, en tanto que México y Canadá fueron aceptados en las negociaciones en octubre de 2012. Finalmente, Japón anunció en marzo de 2013 que los 11 miembros aceptaron su entrada, la cual fue formalizada en julio. Actualmente los países miembros del proceso de negociación del TPP son los siguientes:

Cuadro 1

Incorporación de naciones al TPP

\begin{tabular}{lclc}
\hline País & Año de ingreso & País & Año de ingreso \\
\hline Brunei Darussalam & 2005 & Perú & 2008 \\
Nueva Zelanda & 2005 & Vietnam & 2008 \\
Singapur & 2005 & Malasia & 2010 \\
Chile & 2005 & Mexico & 2012 \\
Estados Unidos & 2008 & Canadá & 2012 \\
Australia & 2008 & Japón & 2013 \\
\hline
\end{tabular}


El TPP parece ser la propuesta concreta más tangible entre estas naciones de la región Asia Pacífico para convertirse en un bloque indispensable de la propuesta Área de Libre Comercio de Asia Pacífico (Free Trade Area of the Asia Pacific - FTAAP, por sus siglas en inglés-) (Fergusson, 2011: 5), una aspiración largamente contemplada pero no materializada por las 21 economías de APEC. Más aún, y ante la imposibilidad de que se cumplan las Metas de Bogor establecidas por APEC en 1994 (la liberalización generalizada del comercio y las inversiones en las economías industrializadas APEC para el año 2010 y para el año 2020 en el caso de aquéllas en vías de desarrollo (APEC, 2012)), y en particular ante la resistencia de estas economías de la región para reducir tarifas arancelarias a los productos agrícolas o en aumentar el porcentaje de productos totales con tarifa arancelaria cero (en 2012 fue de un promedio de tan sólo $45.2 \%$ del total de los productos comercializados en la zona APEC), el TPP parece ser la vía más concreta para lograr dichas metas.

En otras palabras, el TPP in-

El TPP es considerado por los países miembros como un acuerdo de libre comercio del siglo xxi o "de próxima generación", por algunos especialistas calificado como un "súper TLC con esteroides" (Carpenter, 2013) y su negociación como de la más alta importancia y con enormes implicaciones a mediano y largo plazos. Es considerado como la iniciativa de libre comercio más ambiciosa en el mundo por su amplia cobertura (que no sólo involucra liberalización del comercio regional) y la naturaleza de los regímenes políticos de los países miembros tenta resarcir parcialmente (en términos del número de economías que participan) lo que no ha logrado APEC en su conjunto. El TPP es considerado por los países miembros como un acuerdo de libre comercio del siglo XXI o "de próxima generación", por algunos especialistas calificado como un "súper TLC con esteroides" (Carpenter, 2013) y su negociación como de la más alta importancia y con enormes implicaciones a mediano y largo plazos. Es considerado como la iniciativa de libre comercio 
más ambiciosa en el mundo por su amplia cobertura (que no sólo involucra liberalización del comercio regional) y la naturaleza de los regímenes políticos de los países miembros.

Las negociaciones se centran en más de 21 mesas de trabajo, incluyendo agricultura, aduanas, bienes industriales, reglas de origen, textiles, servicios, servicios financieros, movilidad de personas de negocios, inversión, telecomunicaciones, competencia/empresas comerciales del Estado, comercio y medio ambiente, compras de gobierno, derechos de propiedad intelectual, comercio y trabajo, medidas sanitarias y fitosanitarias, obstáculos técnicos al comercio, remedios comerciales, y temas legales/institucionales (Secretaría de Economía, 2012: 5). En este sentido, no sólo es un súper acuerdo de libre comercio, sino un acuerdo que puede de hecho redefinir las economías de estos países en términos de reglas, solución de diferendos, derechos de propiedad intelectual, estándares de seguridad alimentaria, cadenas de producción, reglas de origen, legislaciones nacionales, normas medioambientales, etcétera.

En el aspecto puramente comercial, se estima que el TPP podría ser la respuesta de la región Asia Pacífico ante el evidente fracaso de las negociaciones multilaterales de liberalización del comercio mundial dentro de la Ronda de Doha de la OMC. La repercusión del TPP, una vez firmado, alcanzaría potencialmente a alrededor de $11 \%$ de la población mundial (casi 800 millones de habitantes), e involucrará a cerca de $40 \%$ del PIB mundial y alrededor de un tercio de todo el comercio internacional. En relación con el bloque de 21 economías de APEC, el área TPP (que para mayo de 2013 todavía no incluía a Japón) acumulaba ya un PIB combinado de alrededor de 21 mil millones de dólares estadounidenses, cifra superior a $50 \%$ del total de los miembros de APEC (MTI Singapore, 2013).

\section{Estado de las negociaciones}

Desde que en marzo de 2010 se llevó a cabo la primera ronda de negociaciones del TPP en Melbourne, Australia, para principios de octubre de 2013 se han llevado a cabo 20 rondas multilaterales, junto con varias sesiones intrasesionales y muchas reuniones bilaterales necesarias para acelerar el proceso. Es importante aclarar que el contenido de las negociaciones no se ha hecho público, ya que los equipos negociadores consideran que la confidencialidad es un aspecto indispensable, necesario para el éxito del acuerdo. 
Las negociaciones están a cargo de los representantes comerciales de los países miembros (cuyas delegaciones generalmente incluyen a funcionarios de otros sectores), quienes se reúnen para presentar las posiciones oficiales, y en el caso de algunos países, recibir retroalimentación externa de grupos de sus propios países (stakeholders) sobre asuntos directamente de interés. Sin embargo, la presentación de las propuestas oficiales en las rondas de negociaciones y en las reuniones bilaterales se supone que ya condensa las peticiones de diversos sectores de la población. El contenido particular de los capítulos a negociación (y los borradores oficiales del texto mismo) no los conocen ni siquiera los legisladores de los países miembros.

Desde la quinceava ronda, el proceso de negociación, al tiempo que se ha acelerado, también se ha dificultado enormemente, principalmente en el área de acceso a mercados y otros rubros muy sensibles - propiedad intelectual, acceso a mercados, medio ambiente y compras de gobierno-. Ahora, tras la ronda número 20 de Bali, Indonesia (octubre de 2013), y ante el evidente conflicto de intereses en el tema agrícola con la entrada de Japón al proceso negociador, algunos países proponen escalonar en fases de 10 años la eliminación arancelaria a diversos productos agrícolas. ${ }^{2}$

En la llamada recta final de las negociaciones, los obstáculos más importantes se vislumbran en las áreas de acceso a los mercado para bienes y productos, inversiones, empresas paraestatales, medio ambiente, derechos de propiedad intelectual (un capítulo particularmente controvertido), y compras de gobierno. Uno de los principales problemas en las negociaciones actuales es la resistencia de algunos países (en particular Australia, Malasia y Vietnam) que se oponen a la inclusión de una cláusula para la solución de disputas entre inversionistas y Estados (la llamada "Cláusula de solución de disputas entre inversionista y Estado" (o "Arreglo de diferencias relativas a inversiones", ISDS por sus siglas en inglés), una cláusula propuesta por Estados Unidos.

2. La ronda de Bali (8 de octubre de 2013) se caracterizó por fuertes discrepancias en el borrador estadounidense sobre el capítulo de medio ambiente, y las negociaciones parecían estancadas en áreas de propiedad intelectual (incluyendo la sección de patentes), inversiones, etc., por lo que, a pesar de las presiones de Estados Unidos, no se pudo hacer referencia alguna a un "acuerdo a nivel político", algo que comprometería a los países negociadores a acelerar el proceso para finales del año. El comunicado conjunto de los líderes en Bali está en http://libcloud.s3.amazonaws. com/93/6d/d/3274/Bali_TPPsummit.pdf. Sobre la Ronda Bali véase: Adam Russell, "Froman fails to get 'political level' Trans Pacific trade agreement", Friends of Earth, 8 de octubre, 2013, disponible en http://www.foe.org/news/news-releases/2013-10-froman-fails-to-get-political-level-tppagreement 
Facultado por esta cláusula, una empresa multinacional puede demandar a un Estado exigiendo compensación si considera que sus inversiones han sido afectadas por una decisión gubernamental. ${ }^{3}$

Una vez que el acuerdo, que se espera será un documento de unas mil páginas, sea aprobado por los grupos negociadores, deberá pasar al proceso de ratificación en sus respectivos países. Este proceso, un segundo gran obstáculo para el poder legislativo en varias naciones, puede ser largo y, sobra decir, puede ser la oportunidad de algún país para retractarse del acuerdo alcanzado. En el caso de Estados Unidos, la llamada "autoridad de vía rápida" (fast-track authority, formalmente conocida como trade promotion authority) no ha sido renovada por el Congreso estadounidense desde 2007, por lo que la administración Obama no podrá suscribir este tratado desde el Ejecutivo sin estos poderes. Se estima que para finales de este año el Congreso podría otorgar estos poderes al presidente Obama, o bien, pasar el TPP por el proceso tradicional de ratificación ante el Legislativo.

El TPP no es la única propuesta de integración económica regional, aunque sí una de las más ambiciosas. Algunas propuestas son meramente asiáticas, otras de naturaleza transhemisférica. La Asociación de Naciones del Sudeste Asiático (ANSEA) tiene como uno de sus objetivos a corto plazo la creación de una comunidad económica ANSEA para el año 2015 a fin de alcanzar una integración económica regional con un posible mercado único. Otro mecanismo es la Cumbre del Este de Asia (EAS), un esfuerzo de los 10 países de ANSEA más ocho naciones colindantes con el Océano Pacífico y el Océano Índico para promover, entre otras, la cooperación económica. Un tercer modelo de integración económica regional es la Alianza del Pacífico, que centrado en

3. “TPP tariff talks on Japan's key farm products likely to begin in Sept.", Global Post, 26 de agosto, 2013, disponible en http://www.globalpost.com/dispatch/news/kyodo-news-international/130826/ tpp-tariff-talks-japans-key-farm-products-likely-begin. Según este mecanismo, que ya existe en algunos tratados bilaterales en el mundo (el TLCAN en su capítulo 11, por ejemplo), una empresa puede invocar la formación de tribunales de arbitraje para demandar a otro Estado si se agotan los mecanismos previos de solución de controversias en caso de verse afectados por una decisión (violaciones a los términos de las inversiones, restricciones en las transferencias de ganancias, o expropiaciones, entre otros muchos casos). Ya sea dentro del Centro Internacional de Arreglo de Diferencias Relativas a Inversiones (ICSID) del Banco Mundial, de las reglas de arbitraje de la ONU (a través de la UNCITRAL), o de otros mecanismos de arbitraje, algunas naciones parecen tener reservas de que la interpretación de las normas consuetudinarias internacionales (costumbres internacionales) puedan afectar la aplicación de leyes nacionales vigentes en el país receptor de la inversión. 
México, Chile, Perú y Colombia, tiene el potencial de sumar en el futuro otros socios comerciales de la Cuenca del Pacífico.

Probablemente el proyecto más ambicioso, después del TPP, sea el Acuerdo de Asociación Económica Regional Total (Regional Comprehensive Economic Partnership, RCEP por sus siglas en inglés), una nueva iniciativa para enlazar a los 10 países de ANSEA y sus socios con los que este bloque mantiene acuerdos de libre comercio, a decir, Australia, India, China, Japón, Corea del Sur y Nueva Zelanda (el grupo original de ANSEA Más Seis, que integraban exclusivamente la Cumbre del Este de Asia hasta 2011). Éste es un nuevo mecanismo de negociación lanzado a principios de 2013, programado para su firma en 2015, y que se espera se convierta en el bloque comercial más grande del mundo (por la participación de China y la India, indudablemente). En este acuerdo, ANSEA es pieza central para lograr sus metas, que aparte de abarcar el comercio de bienes y servicios, inversión y cooperación, tiene el objetivo explícito de servir como un vehículo para apoyar la ampliación de redes de producción global y reducir las deficiencias de los diversos acuerdos comerciales que los países asiáticos han suscrito ${ }^{4}$ (Sinha y Geethanjali, 2013).

Ante estos proyectos, sin embargo, el TPP es en verdad único. La naturaleza particular del TPP es que no contempla la participación de China (a diferencia de la EAS y el RCEP), por lo que se considera un bloque encabezado por Estados Unidos que hará frente al gigante asiático. Además, el TPP ya cubre un espectro geográfico verdaderamente transpacífico (como todavía no lo es la Alianza del Pacífico en su carácter todavía latinoamericano o ANSEA por su carácter puramente este-asiático). Más aún, el TPP está ya en una etapa de negociación avanzada, y cubre sobre todo aspectos mucho más ambiciosos que el simple libre comercio. Y es en este gran proyecto que México apuesta gran parte de su futuro.

\section{Lógica geopolítica de la inserción de México en el TPP}

Como una de las más importantes decisiones transexenales de la administración de Felipe Calderón Hinojosa a la de Enrique Peña Nieto, la participación de México en el TPP tiene actualmente el objetivo principal de permitir al país pertenecer a un mecanismo de asociación regional que ayude al crecimiento

4. Actualmente existen cinco acuerdos de libre comercio entre ASEAN más otro socio y 23 TLC bilaterales ratificados en la región. 
económico y la prosperidad de la nación (PND, 2013: 9). Aquí, el contexto internacional y el reconocimiento de importantes ajustes en el sistema internacional y los nuevos retos a escala global (incluyendo, entre otros, la gravitación del dinamismo económico mundial en la región Asia Pacífico, la crisis en las negociaciones multilaterales de la OMC, y la vulnerabilidad de muchas economías ante posibles crisis financieras o crediticias) han obligado a México a explorar nuevos modelos de integración económica regional. El recién elaborado Plan Nacional de Desarrollo 2013-2018 estipula:

\begin{abstract}
[...] el cambio en la arquitectura geopolítica representa una oportunidad para países como el nuestro. Las nuevas dinámicas de crecimiento económico y las transformaciones de política interna, que afectan a diversas naciones desarrolladas, abren una ventana en el escenario internacional para que países emergentes desempeñen un papel más destacado (PND, 2013: 14).
\end{abstract}

Aquí, dos premisas son básicas para entender la inserción de México en el proceso de negociación del TPP y su futura adhesión: en primer lugar, la apuesta ante las supuestas ventajas del libre comercio y el reconocimiento de que el proteccionismo comercial daña la economía mexicana en los intercambios con el exterior; en segundo lugar, que México necesita ahora más que antes de una mayor proyección internacional, tanto a nivel económico en el intercambio de bienes y capitales (considerando sus ventajas geográficas), como en el político y multilateral (aprovechando el prestigio de su diplomacia en negociaciones internacionales). A partir de uno de los principales objetivos del PND, ${ }^{5}$ el Gobierno mexicano ha decidido implementar la estrategia general de impulsar y profundizar la política de apertura comercial para incentivar la participación del país en la economía global y la integración regional mediante acuerdos económicos estratégicos. En consecuencia, como una de sus principales líneas de acción está:

Impulsar activamente el Acuerdo Estratégico Transpacífico de Asociación Económica, como estrategia fundamental para incorporar a la economía mexicana en la dinámica de los grandes mercados internacionales (PND, 2013: 151).

5. El objetivo 5.3., Reafirmar el compromiso del país con el libre comercio, la movilidad de capitales y la integración productiva. 
La participación de México en las negociaciones del TPP es relativamente reciente, ya que, como se señaló líneas arriba, inició desde 2012. Durante las reuniones realizadas dentro del marco de la Cumbre del Grupo de los Veinte (G20) en Los Cabos, Baja California, los países negociadores del TPP dieron la bienvenida formal a México y Canadá para incorporarse a las negociaciones de este acuerdo; el 8 de octubre del mismo año México fue aceptado como miembro pleno del TPP (Secretaría de Economía, 2013a). Un mes después, ya contando con la participación plena mexicana, se llevó a cabo una ronda "intermedia" en Los Cabos para abordar temas de coherencia regulatoria y desarrollo, temas que necesitaban de más trabajo entre las delegaciones negociadoras.

La lógica detrás de la decisión de la pasada administración Calderón de iniciar su participación en las negociaciones del TPP fue tanto económica como geopolítica. Según datos de la Secretaría de Economía (2013a), México se mantenía en 2012 como la decimocuarta economía mundial, el decimoprimer exportador mundial, el primer exportador en América Latina y el quinto receptor de inversión extranjera directa (IED) entre las economías emergentes. Si bien un considerable porcentaje de las exportaciones mexicanas es para el mercado de América del Norte, se sabe que el porcentaje del crecimiento anual 2005-2012 en esa región se mantuvo sólo al nivel de 8.3\%, mientras que para la región de Asia fue de 24.2\% (Secretaría de Economía 2013a). Importante destacar, dentro de la lógica de mirar a la región de Asia Pacífico, es el hecho de que durante el mismo periodo el crecimiento del comercio total con los países del TPP, excluyendo Japón, fue de 64.5\%. Así pues, la región Asia Pacífico parece ser la puerta de entrada a un crecimiento comercial de México con el exterior a inicios del siglo XxI.

Desde el punto de vista geopolítico, la ubicación en la región Asia Pacífico de todos sus miembros, y un comercio - principalmente marítimo- entre Estados con proximidad geográfica, le imprime al TPP una ventaja por encima de la que actualmente goza México individualmente con cada uno de los socios comerciales con los que mantiene acuerdos de libre comercio en la Cuenca del Pacífico (con excepción de EUA y Canadá). ${ }^{6}$ Se estima que el comercio total durante el año 2012 entre los entonces 11 países negociadores del TPP,

6. Perú, Japón, Uruguay, Guatemala, Honduras y El Salvador, Chile, Nicaragua, Colombia y Costa Rica. 
excluyendo a Japón, alcanzó los 6,400 millones de dólares (Secretaría de Economía, 2013a).

Para México, importantes razones parecen justificar su participación en el TPP. Entre ellas las más relevantes son:

1. Pertenecer al bloque que representaría un $40 \%$ del PIB mundial y un tercio de las exportaciones mundiales.

2. Ser parte de un mercado potencial, como se mencionó líneas arriba, de casi 800 millones de habitantes.

3. Participar en un bloque formado en su configuración actual bajo iniciativa de Estados Unidos, el principal socio comercial de México.

4. Incursionar en la región Asia Pacífico, la más dinámica desde la perspectiva económica.

5. Vincular indirectamente nuestro crecimiento económico con importantes socios TPP que por su lado mantienen dinamismo económico con India y China, importantes polos económicos mundiales en Asia.

6. Buscar formas de combatir el proteccionismo a nivel global asegurando accesos preferenciales a los productos mexicanos.

Más aún, desde una perspectiva geopolítica, la cercanía de México a Estados Unidos, todavía el principal mercado mundial, ofrece ventajas de acceso directo terrestre desde nuestro país, y una posición privilegiada en las rutas marítimas comerciales del continente americano, tanto para los socios TPP del hemisferio norte (Estados Unidos y Canadá) hasta los del hemisferio sur (Perú y Chile).

Las negociaciones por parte de México están a cargo de la Secretaría de Economía (Ildefonso Guajardo Villarreal), y en particular de la Subsecretaría de Comercio Exterior (Francisco de Rosenzweig Mendialdúa), apoyados a su vez por oficinas de varias dependencias de la Administración Pública Centralizada. ${ }^{7}$ Entre las agrupaciones del sector privado con las que el Gobierno federal informa tener permanente contacto en temas directamente relacionados con la negociación del TPP está la Coordinadora de Organismos Empresariales de

7. Otras dependencias incluyen las Secretarías de Medio Ambiente y Recursos Naturales, Trabajo y Previsión Social, Función Pública y Agricultura, Ganadería, Desarrollo Rural, Pesca y Alimentación; el Servicio Nacional de Sanidad, Inocuidad y Calidad Agroalimentaria (Senasica), la Comisión Federal para la Protección contra Riesgos Sanitarios (Cofepris), del Instituto Nacional del Derecho de Autor (Indautor), el Instituto Mexicano de la Propiedad Industrial (IMPI), la Comisión Federal de Competencia (CFC) y el Servicio de Administración Tributaria (SAT). 
Comercio Exterior (COECE), la Confederación de Cámaras Industriales de los Estados Unidos Mexicanos (Concamin) y el Consejo Empresarial Mexicano de Comercio Exterior, Inversión y Tecnología (COMCE).

Y sin embargo, este proceso dista mucho en México, como en los demás países participantes del pacto, de ser transparente. Como resultado del hermetismo total imperante en las mesas oficiales de negociaciones, es de esperarse que el contenido de éstas, los textos de la negociación, así como las razones para aceptar o rechazar las propuestas de las delegaciones, sea confidencial y lo continúe siendo en el futuro próximo. Entre los pocos documentos emitidos por las administraciones Calderón y Peña Nieto están un informe de la Secretaría de Economía (2012a) a la Cámara de Senadores en noviembre de 2012 y las Memorias documentales del sexenio (Secretaría de Economía, 2012), así como el informe de la misma Secretaría sobre dos reuniones sobre el tema, una con el Senado de la República (Secretaría de Economía, 2013) y otra con la sociedad civil (Secretaría de Economía, 2013a), sendos informes que, sin embargo, muestran casi exclusivamente en presentaciones Power Point, los potenciales beneficios de la apertura comercial y la integración a los mercados internacionales en cifras muy optimistas.

\section{El TPP dentro del proyecto de desarrollo y la política exterior de México: límites al optimismo}

La participación de México en las negociaciones del TPP, si bien fue iniciada en la pasada administración Calderón, obedece ahora y se ha incorporado a la serie de objetivos trazados en el PND, principalmente en los rubros de desarrollo económico y de política exterior, como se señaló líneas arriba. Dentro de los cinco grandes rubros de análisis dentro del PND sobre el futuro rumbo del país (un país en paz, incluyente, con educación de calidad, próspero y con responsabilidad global), la participación en el TPP incidiría en dos de ellos, en un país próspero y uno con responsabilidad global.

En relación con el primero, este acuerdo transpacífico ayudaría, en teoría, a impulsar la competitividad de la planta productiva del país a nivel internacional, profundizando la inserción efectiva de México en la economía mundial (Secretaría de Economía, 2012a). Considerando que el mercado de América del Norte seguirá siendo un destino natural de gran parte de los productos mexicanos, se estima que con este acuerdo se fomentará la integración de productos mexicanos a las exportaciones de Estados Unidos a Asia y de Mé- 
xico a Estados Unidos con insumos asiáticos. Además, se obtendrán insumos que no se producen en México (algo cada vez más característico en el sector manufacturero), habrá más certidumbre jurídica para nuestras inversiones y para las inversiones extranjeras en nuestro país, y se promoverá la cooperación y alianzas comerciales en negocios internacionales. La Secretaría de Economía (2013a) ha identificado seis áreas de importantes beneficios que México podrá gozar una vez entrado en vigor el TPP:

1. Se alcanzaría una zona de acceso preferencial a 11 de las economías más importantes del mundo.

2. Acumulación de origen y obtención de reciprocidad de los Estados miembros TPP.

3. Diversificación de mercados.

4. Aumentar el atractivo de México como destino de inversión extranjera directa (IED).

5. Posibilidad de colocar productos mexicanos por un valor de alrededor de 150 mil mdd en varios sectores clave de la exportación.

6. Posibilidad de exportar a otros mercados productos terminados aprovechando la ventaja de que un $90 \%$ de nuestras importaciones de Asia Pacífico son productos intermedios o de capital.

En relación con la proyección a futuro de México como actor con responsabilidad global, la entrada del país al TPP tiene su propia lógica dentro de la actual política exterior. El Gobierno federal considera que la participación del país en este acuerdo transpacífico debe reflejar la política de un país que desea ser una fuerza positiva y propositiva en el mundo, que reacciona ante importantes retos tanto globales como regionales - particularmente el impulso a la competitividad y la apertura de mercados en el mundo-. Dentro del diagnóstico de la actual situación internacional, la actual administración considera que las negociaciones comerciales internacionales son básicas para fortalecer la presencia del país en los mercados mundiales. Para enfrentar esta realidad, un importante plan de acción de la estrategia del PND $^{8}$ en materia de política exterior incluye en consecuencia:

8. Estrategia 5.1.4., Consolidar a Asia-Pacífico como región clave en la diversificación de los vínculos económicos de México con el exterior y participar activamente en los foros regionales. 
Incrementar la presencia de México en la región (Asia Pacífico) a fin de ampliar y profundizar las relaciones diplomáticas, comerciales y de cooperación con países que por su peso económico y proyección internacional constituyan socios relevantes [...]

[...] Apoyar la negociación del Acuerdo Estratégico Transpacífico de Asociación Económica y la expansión de intercambios (PND, 2013: 148).

Sin embargo, y en tanto no se conozcan los términos de las negociaciones del texto final del TPP, estos objetivos económicos y políticos, que en teoría deben lograrse dentro del presente sexenio, en la realidad no pasan de ser grandes expectativas, mientras que al mismo tiempo el país confronta importantes peligros derivados de este acuerdo de nueva generación. En primer lugar no hay una hoja de ruta sobre cómo blindar la economía mexicana ante el posible embate de importaciones masivas sin cuotas arancelarias, particularmente ante la realidad de la poca competitividad de una gran cantidad de productos mexicanos.

Hasta el momento no se conoce la posición de México sobre la necesidad o no de proteger productos sensibles del sector agrícola — donde sí tenemos competitividad-, como ya públicamente lo han exigido otros países (Japón por ejemplo). Tampoco se sabe qué tipo de mecanismos tiene pensado utilizar México para protegerse de posibles disputas interpuestas por empresas transnacionales e inversionistas extranjeros, en casos de millonarias demandas (algo de particular interés para Estados Unidos y de suma preocupación para más naciones como Australia y Malasia), el tipo de mecanismo de arbitraje que pueda nuestro país invocar en estos casos, ${ }^{9}$ o bien, la posición oficial de México para la defensa de pymes frente al nuevo acuerdo.

Tampoco se sabe la posición del Gobierno mexicano en relación con protección excesiva dentro del TPP de derechos de propiedad intelectual y marcas registradas, así como del impacto en la producción creativa en el país. ${ }^{10} \mathrm{Un}$

9. México, al igual que Canadá y Vietnam, es una nación negociadora del TPP que no participa en la Convención para la Solución de Disputas sobre Inversiones CSID, aunque en los casos de demandas interpuestas bajo el capítulo 11 del TLCAN desde su entrada en vigor en 1994 ha aceptado la formación de tribunales arbitrales bajo las reglas adicionales del Centro Internacional para la Solución de Disputas sobre Inversiones ICSID.

10. Uno de los dos borradores filtrados del TPP es una versión estadounidense del 10 de febrero de 2011 del capítulo sobre derechos de propiedad intelectual que presenta claramente el interés de la parte estadounidense de proteger marcas registradas, marcas con referencias geográficas, derechos de prohibición de almacenamiento de producción intelectual en medios electrónicos -incluso temporalmente-, y derechos de autor con duraciones de hasta 125 años después de creada la obra. 
tema particularmente importante para México es la protección del sistema de salud y la amplia cobertura de la población con medicamentos genéricos y la amenaza de las posibles implicaciones que puede tener el TPP en las patentes de estos productos.

En resumen, hay muchas expectativas y poca información (Navarrete, 2013); ${ }^{11}$ el propio proceso de negociación y los términos aceptados podrían afectar los mismos objetivos del PND acotando el propio desarrollo económico que se busca en el actual plan sexenal.

\section{El camino por recorrer: a modo de consideraciones finales}

El proceso de negociación parece tener una cuenta regresiva, por lo que hay un corto camino por delante, aunque probablemente será el más difícil de transitar. Es improbable que un acuerdo general, por no mencionar un texto final del acuerdo, se alcance a finales de 2013. Ésta es una preocupación compartida por varios gobiernos e incluso por el propio director ejecutivo de APEC, Alan Bollard (Fallow, 2013). ${ }^{12}$ Es importante aclarar que existen importantes asuntos pendientes para todos los países miembros, algunos virtualmente insuperables, entre los cuales están los siguientes:

1. Negociaciones bilaterales entre Estados Unidos y Japón sobre estándares de seguridad en productos alimenticios y homologación de normas en el sector automotriz.

2. Falta de disposición por parte de Japón de abolir totalmente sus tarifas arancelarias a las importaciones de arroz, trigo, carne de res y puerco, lácteos y azúcar, uno de los temas políticamente más sensibles en ese país, pero que están exigiendo abiertamente Chile, Brunei y Singapur.

3. Posición de Australia de insertar excepciones en las negociaciones en el rubro de propiedad intelectual y armonización de las estipulaciones sobre este tema y su propia legislación que está ahora en proceso de reforma.

4. Estancamiento en las negociaciones del sector de reglas de origen con Vietnam, país que desea incluir en las reducciones arancelarias sus pro-

El documento está disponible en línea en http://keepthewebopen.com/assets/pdfs/tpp\%20ip\%20 chapter\%20proposal.pdf

11. El embajador Jorge Eduardo Navarrete lo califica de proceso "opaco".

12. Bollard duda que para final de año se llegue a un acuerdo sustancial. 
ductos textiles que contienen fibras de China, un país no miembro del proceso TPP. ${ }^{13}$

5. Aceptación o no por parte de varios países de propuestas de Estados Unidos para incluir excepciones en los mecanismos internacionales de solución de controversias para productos de tabaco (Too, 2013).

6. Reticencia ante la insistencia de Estados Unidos de incluir en el rubro de propiedad intelectual términos que permitan la protección legal internacional a patentes corporativas sobre vida animal y vegetal, facultando a empresas poseer derechos de propiedad intelectual sobre códigos genéticos.

Más aún, desde una perspectiva a largo plazo, es necesario un debate sobre si el TPP es o no un proyecto secuestrado por Estados Unidos desde 2008 que básicamente excluye a China del pacto regional y de un mercado regional en el que los intereses chinos influyen en el comercio y la inversión. Si es verdaderamente un acuerdo abierto a la adhesión de nuevos miembros, es imprescindible un debate sobre la necesidad de que China - la segunda potencia económica mundial- llegue a participar, disipando así las sospechas de que el TPP es un bloque comercial anti-China en la región Asia Pacífico. Algunos políticos y países ya se han manifestado abiertamente a favor de la entrada de China, destacando entre ellos un ex primer ministro de Australia. ${ }^{14}$

Desafortunadamente, el TPP parece ser realmente el principal instrumento de Estados Unidos para impulsar su propia estrategia de crecimiento económico en la región: la entrada de Washington durante la administración Bush y la confirmación de la administración Obama de participar (liderar) en el proceso de negociación es uno de los pilares de la estrategia del rebalancing de Estados Unidos hacia esta región del planeta, y es el aspecto comercial de la proyección de esta superpotencia en Asia Pacífico en el nuevo siglo. Y dentro de esta lógica, la exclusión de China de este pacto no sólo es a todas luces intencional, sino que ya abiertamente parece ser también un instrumento

13. "Japan proposes tariff cuts for products sourced from TPP countries", The Japan Times, 29 de agosto, 2013, disponible en http://www.japantimes.co.jp/news/2013/08/29/business/japan-proposestariff-cuts-for-products-sourced-from-tpp-countries/\#.uiyyad_9zbx

14. Kevin Rudd urgió a los gobiernos de las naciones TPP a dejar la puerta abierta a China en el futuro. ("Rudd says China welcome into TPP", The Australian, 27 de agosto, 2013, disponible en http:// www.theaustralian.com.au/news/breaking-news/rudd-says-china-welcome-into-tpp/storyfn3dxiwe-1226704825781). 
para presionar a China en diversos temas, como propiedad intelectual. ${ }^{15} \mathrm{En}$ respuesta, el TPP ha tenido como una de sus consecuencias el impulsar el mecanismo RCEP entre ASEAN Más Seis y de nutrir la intención de Beijing de sumarse primero como observador y luego posiblemente como miembro pleno de la Alianza del Pacífico. Ante la ausencia del presidente estadounidense Barack Obama en la reunión de líderes de EAS y de la cumbre APEC en Bali en octubre, Beijing aprovechó la oportunidad para mostrar que el modelo RCEP de un futuro mercado integrado es una viable alternativa con la participación, inversión y compromiso de China. ${ }^{16}$

El TPP es ciertamente un proyecto muy ambicioso que podría acelerar, aun de forma escalonada, las metas largamente esperadas por APEC sobre comercio libre y sin aranceles, y en este sentido representa la oportunidad más tangible ante la crisis de confianza en APEC y la OMC. Sin embargo, a pesar de ser un modelo importante de integración y cooperación regional, no debe representar la única opción, ni para México ni para otras economías que aspiran a entrar al acuerdo (como Taiwán y Filipinas). Como un acuerdo de próxima generación, su alcance sobrepasa por mucho el aspecto de libre comercio y tiene ramificaciones que todavía no acaban de ser evaluadas: establecerá las reglas de las relaciones económicas, comerciales e incluso jurídicas y políticas entre países de la región Asia Pacífico, y entre ellos y las poderosas corporaciones multinacionales que deseen operar en esa región.

Grupos que se oponen al TPP han advertido ya que muchas cláusulas que al parecer se están negociando, pueden afectar la propia soberanía nacional (en particular en el caso de demandas por parte de empresas transnacionales a Estados bajo el ya mencionado esquema ISDS). ${ }^{17}$ Así, ante la posible jurisdicción

15. Durante una conferencia de prensa ofrecida el 8 de octubre de 2013, el presidente Obama dijo por primera vez que "Estamos tratando de elevar el nivel de estándares, por ejemplo, en la protección de la propiedad intelectual, que a veces es un gran problema en China. Y si podemos llegar a un acuerdo comercial con los otros países de Asia que diga que debes proteger la propiedad intelectual de la población, eso nos ayudará en nuestras negociaciones con China". La conferencia de prensa está disponible en http://infojustice.org/wp-content/uploads/2013/10/obama-10082013.pdf

16. Demetri Sevastopulo, Shawn Donnan y Ben Bland, "Obama's absence boosts China trade deal", Financial Times online edition, octubre 15, 2013, disponible en http://www.ft.com/cms/ s/0/07d739c2-3556-11e3-952b-00144feab7de.html\#axzz2ienimvky

17. En el año 2012 se filtró a la opinión pública el borrador del capítulo sobre inversiones donde queda de manifiesto este tipo de mecanismo negociándose para la solución de controversias entre inversionistas y Estados, procedimientos de arbitraje y las leyes internacionales aplicables a este tipo de disputas. El documento está disponible en línea en http://www.citizenstrade.org/ctc/wpcontent/uploads/2012/06/tppinvestment.pdf 
de tribunales de arbitraje internacional (que no responden a la ciudadanía de un país, como el Poder Legislativo), un país vería limitada su capacidad de aprobar leyes, definir políticas públicas, asignar contratos, licitar libremente contratos de inversión, proteger a grupos económicos menos favorecidos en su territorio, etc. En otras palabras, minar la habilidad de los gobiernos de regular a favor del interés público (Citizen Trade Campaign, 2012).

Obviamente estos riesgos no son mencionados por los grupos negociadores cuando informan a sus respectivos poderes legislativos: en el caso de México es evidente que estos riesgos no se incluyen en las sesiones informativas al Senado o a la sociedad civil. Entre los principales riesgos que se mencionan son los que correría el país de no participar en este acuerdo regional (principalmente 1, desaprovechar la coyuntura de entrar a mercados con gran potencial; 2, profundizar la erosión de preferencias del país en el mercado estadounidense; y 3, dejar que Chile y Perú obtengan mejores condiciones que México de acceso a Estados Unidos) (Secretaría de Economía, 2012a: 11).

Más allá de los accesos a mercados y la liberalización del comercio, el Gobierno debe proteger la planta productiva, fortalecer las pymes, coordinar de cerca las propias políticas de propiedad intelectual para promover la innovación en ciencia y tecnología, y preparar mecanismos de respuesta ante posibles disputas con inversionistas de otras naciones, ${ }^{18}$ entre otras medidas para enfrentar riesgos mencionados líneas arriba.

Para nuestro país, las preguntas que quedan pendientes de responder son: ¿realmente el equipo negociador conoce todas las implicaciones sociales, políticas y jurídicas, aparte de las económicas, de participar en un acuerdo cuyo contenido sólo ellos conocen? ¿Se pueden lograr las metas del PND aceptando los términos negociados en las rondas finales del TPP, o el país está subiéndose a un tren del que realmente desconoce a ciencia cierta a dónde nos llevará? Muy por encima del posible prestigio internacional que puede dar a México participar en este "súper acuerdo" del siglo XXI, ¿los poderes de la Unión y la planta productiva del país están listos para el embate de un TPP moldeado a los intereses empresariales que representa el liberalismo a ultranza de Estados Unidos?

18. Desde la entrada en vigor del TLCAN, un total de 13 demandas relevantes han sido interpuestas por parte de empresas estadounidenses contra México sobre controversias relativas a IED, un número que podría palidecer en comparación con el potencial peligro de aquellas empresas transnacionales que, avaladas por cláusulas del TPP, lleguen a afectar el interés nacional. 
Ante todo hay una responsabilidad social frente a la población de nuestro país y ante las próximas generaciones, que gozarán (o sufrirán) los frutos de este acuerdo.

\section{Referencias bibliográficas}

APEC (2012), APEC's Bogor Goals Progress Report, 13 de agosto, disponible en http://www.apec.org/about-us/about-apec/achievements-and-benefits/ /media/files/aboutus/achievementsbenefits/2012_bg_reports/ apec_bogorgoalsprogressreport_13aug2012.ashx

Carpenter, Zoe (2013), "Keeping a Massive Trade Deal Out of the Fast Lane", The Nation, 27 de agosto), disponible en http://www.thenation.com/ blog/175865/keeping-massive-trade-deal-out-fast-lane\#

Citizens Trade Campaign (2012), The Trans-Pacific Partnership (TPP), disponible en http://www.citizenstrade.org/ctc/wp-content/uploads/2012/03/ TransPacificFactsheet.pdf

Fallow, Brian (2013), "Growth tipped to be more resilient for Asia Pacific", The New Zealand Herald, 28 de agosto, disponible en http://www.nzherald. co.nz/business/news/article.cfm?c_id=3\&objectid=11115276

Fergusson, Ian F., y Bruce Vaughn (2011), The Trans-Pacific Partnership Agreement, 12 de diciembre, Washington, DC: Congressional Research Service.

Global Post (2013), “тPP tariff talks on Japan's key farm products likely to begin in Sept.", Global Post, 26 de agosto, disponible en http://www. globalpost.com/dispatch/news/kyodo-news-international/130826/tpptariff-talks-japans-key-farm-products-likely-begin

Gobierno de la República (2013), Plan Nacional de Desarrollo 2013-2018, México: Gobierno de la República, disponible en http://pnd.gob.mx/ wp-content/uploads/2013/05/pnd.pdf

MTi Singapore, Ministry of Trade and Industry, (2013), " $16^{\text {th }}$ Round of TransPacific Partnership (TPР) in Singapore, March 4-13”, Press Release, 1 de marzo, disponible en http://www.sice.oas.org/tpd/tpp/negotiations/ round16_e.pdf

Navarrete, Jorge Eduardo (2013), “La TPP en Lima”, La Jornada, 23 de mayo, disponible en http://www.jornada.unam.mx/2013/05/23/ opinion/021a2pol

Russell, Adam (2013), "Froman fails to get 'political level' Trans Pacific Trade Agreement", Friends of Earth, 8 de octubre, disponible en http://www. 
foe.org/news/news-releases/2013-10-froman-fails-to-get-political-leveltpp-agreement

Secretaría de Economía (2012), Memorias documentales, Dirección General de Negociaciones Multilaterales y Regionales -Acuerdo de Asociación Transpacífico (TPP), 2006-2012, México, DF, Secretaría de Economía, disponible en http://www.economia.gob.mx/files/transparencia/informe_APF/ memorias/14_md_tpp_sce.pdf

- - (2012a), Informe a la Cámara de Senadores del H. Congreso de la Unión sobre el inicio de negociaciones formales del Acuerdo de Asociación Transpacífico (TPP) entre México y los países del TPP, México, DF: Secretaría de Economía, disponible en http://www.economia.gob.mx/files/comunidad_negocios/ comercio_exterior/inf_senado_inicio_negociaciones_tpp.pdf

- - (2013), Reunión de Trabajo con el H. Senado de la República. Acuerdo de Asociación Transpacífico TPP, 27 de febrero, México, DF: Secretaría de Economía.

-— (2013a), Acuerdo de Asociación Transpacífico TPP. Reunión con la sociedad civil, 26 de febrero, México: Subsecretaría de Comercio Exterior, disponible en http://www.economia.gob.mx/files/comunidad_negocios/ comercio_exterior/presentacion_tpp_soc_civil_26feb2013.pdf

Sevastopulo, Demetri, Shawn Donnan, y Ben Bland (2013), “Obama's absence boosts China trade deal", Financial Times online edition, octubre 15, disponible en http://www.ft.com/cms/s/0/07d739c2-3556-11e3-952b00144feab7de.html\#axzz2ienimvky

Sinha Rohit, y Geethanjali Nataraj (2013), "Regional Comprehensive Economic Partnership (RCEP): Issues and Way Forward”, The Diplomat, 30 de julio, disponible en http://thediplomat.com/pacific-money/2013/07/30/ regional-comprehensive-economic-partnership-rcep-issues-and-wayforward/

The Japan Times (2013), “Japan proposes tariff cuts for products sourced from TPP countries”, The Japan Times, 29 de agosto, disponible en http://www. japantimes.co.jp/news/2013/08/29/business/japan-proposes-tariff-cutsfor-products-sourced-from-tpp-countries/\#.uiyyad_9zbx

Too, Debbie (2013), "USTR says TPP proposal to contain health exemptions", The Brunei Times, 30 de agosto, disponible en http://www.bt.com.bn/ business-national/2013/08/30/ustr-says-tpp-proposal-contain-healthexemptions -0 
“Trans-Pacific Partnership Leaders Statement, October 8, 2013”, disponible en http://libcloud.s3.amazonaws.com/93/6d/d/3274/bali_tppsummit.pdf Uscanga, Carlos (2011), The Trans-Pacific Strategic Economic Partnership Agreement (TPP). Perspectivas desde México, presentado en el XI Seminario Internacional sobre la Cuenca del Pacífico, Colima, 22-23 de septiembre, disponible en http://apec.ucol.mx/sem11/ponencias/39/sem11_Ponencia_Uscanga.pdf

Ustr Office of the United States Trade Representative (2013), Statement on the 18th Round of Trans-Pacific Partnership Negotiations, 25 de julio, disponible en http://www.ustr.gov/about-us/press-office/press-releases/2013/july/ statement-18th-round-tpp 